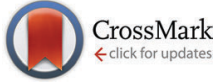

Cite this: Phys. Chem. Chem. Phys., $2015,17,26892$

Received 26th June 2015 , Accepted 14th September 2015 DOI: $10.1039 / c 5 c p 03707 g$

www.rsc.org/pccp

\title{
Surface chemistry of copper metal and copper oxide atomic layer deposition from copper(II) acetylacetonate: a combined first-principles and reactive molecular dynamics study $\dagger$
}

\author{
Xiao Hu, ${ }^{\star a}$ Jörg Schuster, ${ }^{b}$ Stefan E. Schulz ${ }^{\mathrm{ab}}$ and Thomas Gessner ${ }^{\mathrm{ab}}$ \\ Atomistic mechanisms for the atomic layer deposition using the $\mathrm{Cu}(\mathrm{acac})_{2}$ (acac = acetylacetonate) \\ precursor are studied using first-principles calculations and reactive molecular dynamics simulations. \\ The results show that $\mathrm{Cu}(\mathrm{acac})_{2}$ chemisorbs on the hollow site of the $\mathrm{Cu}(110)$ surface and decomposes \\ easily into a $\mathrm{Cu}$ atom and the acac-ligands. A sequential dissociation and reduction of the $\mathrm{Cu}$ precursor \\ $\left[\mathrm{Cu}(\mathrm{acac})_{2} \rightarrow \mathrm{Cu}(\mathrm{acac}) \rightarrow \mathrm{Cu}\right.$ ] are observed. Further decomposition of the acac-ligand is unfavorable on \\ the $\mathrm{Cu}$ surface. Thus additional adsorption of the precursors may be blocked by adsorbed ligands. \\ Molecular hydrogen is found to be nonreactive towards $\mathrm{Cu}(\mathrm{acac})_{2}$ on $\mathrm{Cu}(110)$, whereas individual \\ $\mathrm{H}$ atoms easily lead to bond breaking in the $\mathrm{Cu}$ precursor upon impact, and thus release the surface \\ ligands into the gas-phase. On the other hand, water reacts with $\mathrm{Cu}(\mathrm{acac})_{2}$ on a $\mathrm{Cu}_{2} \mathrm{O}$ substrate through \\ a ligand-exchange reaction, which produces gaseous $\mathrm{H}(\mathrm{acac})$ and surface $\mathrm{OH}$ species. Combustion \\ reactions with the main by-products $\mathrm{CO}_{2}$ and $\mathrm{H}_{2} \mathrm{O}$ are observed during the reaction between $\mathrm{Cu}(\mathrm{acac})_{2}$ \\ and ozone on the $\mathrm{CuO}$ surface. The reactivity of different co-reactants toward $\mathrm{Cu}(\mathrm{acac})_{2}$ follows the \\ order $\mathrm{H}>\mathrm{O}_{3}>\mathrm{H}_{2} \mathrm{O}$.
}

\section{Introduction}

Copper interconnects have been widely used to replace aluminum in ultralarge-scale integrated circuitry due to their low resistivity and superior resistance to electromigration. ${ }^{1}$ Of the various deposition techniques applied for $\mathrm{Cu}$ metallization, electrochemical deposition (ECD) is the preferred choice. However, the ECD process requires conductive seed layers. Moreover, diffusion barrier films are needed to deposit between the $\mathrm{Cu}$ seed layer and the patterned dielectrics in order to prevent the migration of $\mathrm{Cu}$ into the Si substrate and the dielectrics. $^{2}$ So far, ionized physical vapor deposition (iPVD) using ionized sputtering techniques in combination with high re-sputter ratio regimes has been adopted as the desirable method for the barrier and $\mathrm{Cu}$ seed layer deposition. ${ }^{3}$ However, with the ongoing scaling down and aspect ratio increase of devices, iPVD tends to fail due to its inherent nonconformal deposition characteristic.

One promising alternative for making uniform and conformal $\mathrm{Cu}$ thin films is atomic layer deposition (ALD). ALD is a gas-phase

\footnotetext{
${ }^{a}$ Technische Universität Chemnitz, Center for Microtechnologies, Reichenhainer Str. 70, Chemnitz, D-09126, Germany. E-mail: xiao.hu@zfm.tu-chemnitz.de

${ }^{b}$ Fraunhofer Institute for Electronic Nano Systems, Technologie-Campus 3,

Chemnitz, D-09126, Germany

$\dagger$ Electronic supplementary information (ESI) available. The details of the atomic coordinates and validation of the calculation model and the force field parameters. See DOI: $10.1039 / \mathrm{c} 5 \mathrm{cp} 03707 \mathrm{~g}$
}

thin film deposition technique based on sequential, self-terminating reactions between the surface and precursors. ${ }^{4,5}$ The typical ALD process consists of four repetitive steps. The precursor (typically a metal compound) chemisorbs on reactive sites, saturates the surface and releases the reaction by-products. After that, unreacted precursor molecules as well as gaseous byproducts are purged from the reactor. The co-reactant (typically a non-metal compound) is then supplied to clean up the surface of contaminations and deposit the desired species (e.g. oxygen or hydroxyl groups). Finally, another purging phase is introduced to evacuate the excessive reactants and products. By repeating these steps, the film growth is self-limiting, which leads to excellent step coverage and conformal deposition on high aspect ratio structures.

Precursor chemistry plays a key role in ALD. The candidate metal precursors must be volatile, thermally stable, and reactive. Moreover, a low-temperature process (ideally at $\leq 160{ }^{\circ} \mathrm{C}$ ) is desirable for $\mathrm{Cu} \mathrm{ALD}$ in order to avoid the agglomeration of $\mathrm{Cu}$ at elevated temperatures. ${ }^{6}$ Recently, a number of $\mathrm{Cu}$ precursors have been tested for chemical vapor deposition and ALD applications, such as $\beta$-diketiminates, ${ }^{7,8} \beta$-diketonates, ${ }^{9-11}$ amidinates, ${ }^{12,13}$ aminoalkoxides, ${ }^{14}$ guanidinate, ${ }^{15,16}$ iminopyrrolidinate. ${ }^{17,18}$ Among them, the $\mathrm{Cu} \beta$-diketonate family is promising because of its high stability and relatively low vapor pressure. The direct $\mathrm{Cu}$ ALD process using $\mathrm{Cu}(\text { acac })_{2}$ and $\mathrm{H}_{2}$ requires a deposition 
temperature of above $250{ }^{\circ} \mathrm{C}$, and is thus undesirable. ${ }^{19}$ The deposition temperature can be reduced below $100{ }^{\circ} \mathrm{C}$ by utilizing the plasma enhanced ALD technology. ${ }^{20,21}$ However, such a process would lead to high roughness and reduced step coverage of ALD, which may not be applicable for high aspect ratio structures. $^{22}$ On the other hand, several indirect ALD routes to $\mathrm{Cu}$ films have been reported. These approaches consist of two steps: (1) ALD of the $\mathrm{Cu}$ oxide or nitride, and (2) reduction into the metallic $\mathrm{Cu}$ with a reducing agent. Waechtler et al. ${ }^{10}$ investigated the ALD of $\mathrm{Cu}_{2} \mathrm{O}$ thin films on different diffusion barriers (e.g. Ta, TaN, and $\mathrm{Ru})$ using $\left({ }^{n} \mathrm{Bu}_{3} \mathrm{P}\right)_{2} \mathrm{Cu}(\mathrm{acac})(\mathrm{Bu}=$ butyl $)$ and wet oxygen. The deposited $\mathrm{Cu}_{2} \mathrm{O}$ can be reduced easily to $\mathrm{Cu}$ metal using formic acid as the reducing agent assisted by a $\mathrm{Ru}$ catalyst. ${ }^{10}$ Knisley et $a .^{23}$ proposed the low temperature deposition of high purity $\mathrm{Cu}$ metal through the reduction of ALD copper formate using hydrazine. Further theoretical studies revealed that a hydrazine undergoes cleavage to form $\mathrm{NH}_{2}$ moieties, which then abstracts $\mathrm{H}$ of the formate intermediate and spontaneously forms $\mathrm{NH}_{3}$ and $\mathrm{CO}_{2}$ by-products. ${ }^{24}$ More recently, Park et al. ${ }^{25}$ reported $\mathrm{ALD}$ of $\mathrm{Cu}_{3} \mathrm{~N}$ followed by reduced annealing in $\mathrm{H}_{2}$. Such processes may avoid the oxidization of barrier metal below the $\mathrm{Cu}$ seed layer.

There have been a few experimental and theoretical studies on the surface chemistry of $\mathrm{Cu}(\mathrm{I})$ and $\mathrm{Cu}(\mathrm{II}) \beta$-diketonates. In general, the $\mathrm{Cu}(\mathrm{I}) \beta$-diketonates are more reactive compared to $\mathrm{Cu}(\mathrm{II}) \beta$-diketonates. However, the main limitation of $\mathrm{Cu}(\mathrm{I})$ $\beta$-diketonates is that these precursors may easily undergo a disproportionation reaction, which defeats the self-limiting nature of ALD processes. ${ }^{9}$ Previous in situ X-ray photoelectron spectroscopy (XPS) results suggest that the disproportionation of the $\left({ }^{n} \mathrm{Bu}_{3} \mathrm{P}\right)_{2} \mathrm{Cu}(\mathrm{acac})$ precursor, which deposits metallic $\mathrm{Cu}$ and releases gaseous $\mathrm{Cu}(\mathrm{acac})_{2}$, starts above $200{ }^{\circ} \mathrm{C}$ on $\mathrm{SiO}_{2}$ or above $125{ }^{\circ} \mathrm{C}$ on the Co substrate. ${ }^{26,27}$ Hence, the upper temperature limit for copper ALD using this precursor lies below these temperatures. Another important issue regarding $\mathrm{Cu} \beta$-diketonates is the redox chemistry during the ALD. In many cases, especially when metal ALD is desired, the metal center in a precursor is required to undergo an oxidation or reduction step. It is generally assumed that such a step is accomplished during the second ALD half-cycle, which is associated with the promotion of a co-reactant. ${ }^{28}$ Recent surface-science studies, however, illuminated that oxidation state changes in the metal can occur upon precursor activated adsorption on the substrate, involving the partial loss and transformation of ligands. For example, the initial loss of acac-ligands of the $\mathrm{Cu}(\mathrm{acac})_{2}$ precursor was observed at 200 and $235 \mathrm{~K}$ for $\mathrm{Ni}(110)$ and $\mathrm{Cu}(110)$ single-crystal surfaces, respectively. ${ }^{29}$ The formation of a metal-Cu(acac) complex was proposed. An obvious oxidation state change of $\mathrm{Cu}$ has been seen between 250 and $300 \mathrm{~K}$. The adsorbed $\mathrm{Cu}$ (acac) species lose their remaining acac-ligands and $\mathrm{Cu}^{2+}$ is completely reduced to metallic $\mathrm{Cu} .^{29}$

In this work, the surface chemistry of $\mathrm{Cu}(\mathrm{acac})_{2}$ on the $\mathrm{Cu}(110)$ surface is revisited theoretically. Recently, quantum chemistry (QC), in particular density functional theory (DFT) calculations, has become a powerful tool to explicit the ALD chemistry at an atomic scale. ${ }^{30-49}$ Dey et al. ${ }^{31}$ investigated the transmetalation reactions in $\mathrm{Cu}$ ALD using diethylzinc as the reducing agent, following experiments by Lee et al. ${ }^{8}$ Lin et $a l .{ }^{32}$ have investigated the competition between ligand-exchange reactions and surface decomposition of $\mathrm{Cu}(\mathrm{acac})_{2}$ on a $\mathrm{Si}(100)-2 \times 1$ surface. More recently, we have studied the surface reactions of $\left({ }^{n} \mathrm{Bu}_{3} \mathrm{P}\right)_{2} \mathrm{Cu}(\mathrm{acac})$ and $\mathrm{Cu}(\mathrm{acac})_{2}$ precursors on a $\mathrm{Ta}(110)$ surface. ${ }^{33}$ Ta is found to exhibit high activity towards the decomposition of $\mathrm{Cu}$ precursors, which is consistent with earlier results. .,34,35 $^{-3}$ Based on thermodynamic modeling, a combustion-like reaction during the $\mathrm{O}_{3}$ or wet $\mathrm{O}_{2}$ pulse, with $\mathrm{CO}_{2}$ and $\mathrm{H}_{2} \mathrm{O}$ as the main by-products, has been proposed. ${ }^{33}$

An alternative QC approach for investigating ALD chemistry involves ab initio molecular dynamics (AIMD), which have been carried out on the simulation of $\mathrm{SiO}_{2}{ }^{43,44}$ and $\mathrm{HfO}_{2}{ }^{45}$ ALD. As compared to the "static" ab initio calculations, AIMD offers a dynamic description of the time evolution of a chemical reaction. Unfortunately, due to the costs of treating the electronic degrees of freedom, the AIMD study is restricted to model systems consisting of a few hundred atoms and to very short time scales (tens of ps). We thus perform molecular dynamics simulation of $\mathrm{Cu}$ ALD using reactive force field (ReaxFF). ${ }^{50}$ ReaxFF was developed to bridge the gap between QC and empirical force field, which enables the simulation of comparatively large systems for long time scales (e.g. tens of thousands of atoms for the ns scale). ${ }^{50}$ Unlike other traditional non-reactive force fields, ReaxFF offers an accurate description of the bond forming or breaking process. $^{50}$

Previously, the surface reaction of similar metal $\beta$-diketonate of $\operatorname{Ir}(\text { acac })_{3}$ was studied in situ using a quadrupole mass spectrometer and a quartz crystal microbalance. ${ }^{51}$ In that work, $\mathrm{CO}_{2}$ and $\mathrm{H}_{2} \mathrm{O}$ were confirmed as the main reaction by-products during $\mathrm{IrO}_{2}$ ALD. ${ }^{51}$ However, the elementary-step ALD reaction mechanisms are still unclear, since some fast reactions that involve unstable intermediates are difficult to be observed experimentally. Alternatively, reactive molecular dynamics (RMD) simulation provides a possibility to capture the reactions that occurred in ALD in a femtosecond timescale. In the present article, we focus on the surface chemistry of $\mathrm{Cu}(\mathrm{acac})_{2}$ by means of DFT calculations and RMD simulations. It is found that $\mathrm{Cu}(\mathrm{acac})_{2}$ is dissociated easily into a $\mathrm{Cu}$ atom and the acacligands on both metallic $\mathrm{Cu}$ and $\mathrm{Cu}$ oxide surfaces. The dissociated acac-ligands are thermodynamically stable on the surface, and can be removed by co-reactants during the next ALD half-cycle. The mechanisms for the surface reactions between $\mathrm{Cu}(\mathrm{acac})_{2}$ and different co-reactants (i.e. $\mathrm{H}_{2}$, atomic $\mathrm{H}, \mathrm{H}_{2} \mathrm{O}$, and $\mathrm{O}_{3}$ ) are also discussed.

\section{Methodology}

The DFT calculations were performed using the Quantum Espresso (QE) package. ${ }^{52}$ For the modeling of the exchange and correlation interactions the Perdew-Burke-Ernzerhof (PBE) functional within the generalized gradient approximation (GGA) ${ }^{53}$ was used in conjunction with ultrasoft pseudopotentials ${ }^{54}$ and a plane-wave basis set. Kinetic energy cutoffs of $408 \mathrm{eV}$ (for wave functions) 
and $4082 \mathrm{eV}$ (for charge density) were used. The Brillouin zone was sampled using a $2 \times 2 \times 1$ Monkhorst-Pack $k$-point mesh. ${ }^{55}$ To investigate the physisorption of the $\mathrm{Cu}$ precursor on the surface, we used a nonlocal van der Waals density functional (vdW-DF $)^{56}$ as implemented in QE. The geometry was optimized until the total energy changes and all components of all forces are smaller than $1.26 \times 10^{-4} \mathrm{eV}$ and $2.57 \times 10^{-2} \mathrm{eV}^{-1}$, respectively. With the optimized structures, the vibration properties of adsorbed species were calculated using the harmonic approximation based on density-functional perturbation theory. ${ }^{57}$ The minimum energy paths and saddle points were investigated by the climbing image nudged elastic band method (CI-NEB). ${ }^{58,59}$ The charge transfer trends were studied by means of Mulliken population analysis ${ }^{60}$ within the plane-wave CASTEP code, ${ }^{61}$ using similar calculation methods as in QE.

The RMD simulations were carried out using ReaxFF potential as implemented in LAMMPS. ${ }^{62}$ ReaxFF is a general bond order-dependent potential that uses relationships the between interatomic distance and bond order as well as between the bond order and bond energy to describe bond dissociation. ${ }^{50}$ The system energy ( $\left.E_{\text {system }}\right)$ in ReaxFF is composed of a sum of energy terms: ${ }^{50}$

$$
\begin{aligned}
E_{\text {system }}=E_{\text {bond }}+ & E_{\text {under }}+E_{\text {over }}+E_{\mathrm{val}}+E_{\text {pen }}+E_{\text {tors }}+E_{\text {conj }} \\
& +E_{\text {Coulomb }}+E_{\text {vdWaals }}
\end{aligned}
$$

The partial contributions include bond energies $E_{\text {bond }}$, atom under-/overcoordination energies $E_{\text {under }}$ and $E_{\text {over }}$, valence angle energies $E_{\mathrm{val}}$, penalty energies $E_{\text {pen }}$, torsion angle energies $E_{\text {tors }}$, conjugation energies $E_{\text {conj }}$, and non-bonded Coulomb ( $\left.E_{\text {Coulomb }}\right)$ and van der Waals $\left(E_{\text {vdwaals }}\right)$ interaction energies. All bonded energy terms include bond order dependence, which are determined by the local environment of each atom. The Coulomb term $E_{\text {Coulomb }}$ is taken into account for all atom pairs. A shielded Coulomb potential was used to adjust for orbital overlap between atoms that were close together. Atomic charges are computed using the geometry-dependent charge calculation scheme (EEM scheme) of Mortier et al. ${ }^{63}$ The calculation of long-range electrostatic interactions (e.g., via Ewald summation) is eliminated by the use of a seventh-order taper function within a cutoff distance. All other non-bonded interactions (short-range Pauli repulsion and long-range dispersion) are included in the $E_{\mathrm{vdWaals}}$ term. A detailed description of the individual terms can be found in the original paper of van Duin et al. ${ }^{50}$

The ReaxFF parameters for the $\mathrm{Cu}(\mathrm{acac})_{2}$ system considered in the present study have been determined by $a b$ initio calculations performed in previous investigations. ${ }^{64}$ The $\mathrm{Cu} / \mathrm{O} / \mathrm{H}$ parameters were integrated into the glycine force field ${ }^{65}$ by following the suggestions of Huang et al. ${ }^{66}$ These force fields use the same $\mathrm{O} / \mathrm{H}$ parameters and potential functions, making such integration relatively straightforward. ${ }^{66}$ The $\mathrm{Cu} / \mathrm{C}$ bond parameters were not optimized since such bonds were not expected to form, while the non-bonded interactions were obtained from standard combination rules. The RMD simulations are performed in the NVT canonical ensemble (constant number, volume and temperature).
A Nose-Hoover thermostat with a damping constant of $100 \mathrm{fs}$ was used for temperature control. The time step used in RMD simulations was 0.1 fs for the reaction between $\mathrm{Cu}(\mathrm{acac})_{2}$ and $\mathrm{O}_{3}$ and 0.25 fs for the other systems, respectively. Such small time steps are required to capture bond breaking and forming involved in chemical reactions, so that converged results for species evolution can be obtained. The initial system was firstly equilibrated using a low-temperature (at $1 \mathrm{~K}$ ) MD. After the equilibrium, the system temperature was further increased from $1 \mathrm{~K}$ to $600 \mathrm{~K}$ within $20 \mathrm{ps}$ at a uniform rate. Finally, reactive NVTMD simulations were performed at $600 \mathrm{~K}$ for a total simulation time of up to $1 \mathrm{~ns}$. We slightly increase the temperature to accelerate the chemical reaction.

Fig. 1 shows the calculated atomic structure of the $\mathrm{Cu}(\mathrm{acac})_{2}$ precursor. The predicted and experimental bond lengths and bond angles are listed in Table 1. A good agreement is observed between theoretical and experimental results. ${ }^{67}$ The only exception is that ReaxFF predicts slightly larger $\mathrm{C} 1-\mathrm{O}$ bond length $(0.16 \AA)$ and $\mathrm{Cu}-\mathrm{O}-\mathrm{C} 1$ angle $\left(4.8^{\circ}\right)$ values. A more systematic comparison of the results from DFT and ReaxFF is shown in the next section. In DFT calculations, the $\mathrm{Cu}(110)$ surface was modeled using a $\mathrm{p}(4 \times 4)$ supercell with periodic four-layer slab models. In the case of RMD simulations, larger surface models consisting of a four-layer slab for $\mathrm{p}(22 \times 30)-\mathrm{Cu}(110)$ $\left(79.52 \times 76.68 \AA^{2}\right)$, and a nine-layer slab for $\mathrm{p}(12 \times 16)-\mathrm{Cu}_{2} \mathrm{O}(111)$ $\left(72.46 \times 83.67 \AA^{2}\right)$ and for $\mathrm{p}(14 \times 12)-\mathrm{CuO}(111)\left(80.76 \times 73.70 \AA^{2}\right)$ were employed, respectively. To simplify our models, only stoichiometric surfaces were considered for $\mathrm{Cu}_{2} \mathrm{O}(111)$ and $\mathrm{CuO}(111)$. During the simulations, the bottom two layers of $\mathrm{Cu}(110)$, and four layers of $\mathrm{Cu}_{2} \mathrm{O}(111)$ and $\mathrm{CuO}(111)$ were fixed, respectively. To investigate the surface reaction between $\mathrm{Cu}(\mathrm{acac})_{2}$ and different co-reactants, $24 \mathrm{Cu}(\mathrm{acac})_{2}$ precursors were initially placed on

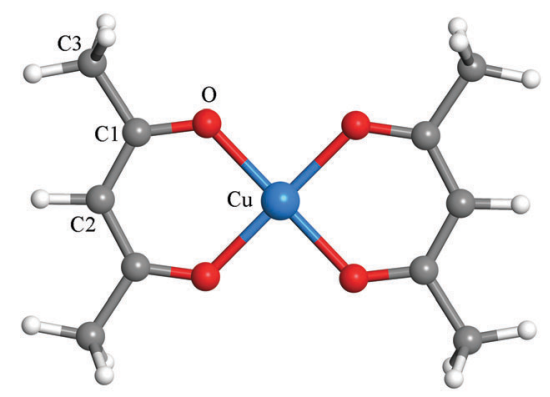

Fig. 1 Structure of the $\mathrm{Cu}(\mathrm{acac})_{2}$ precursor.

Table 1 Comparison between the experimental (from ref. 67) and calculated bond lengths $(\AA)$ and angles $\left(^{\circ}\right)$ of the $\mathrm{Cu}(\mathrm{acac})_{2}$ molecule

\begin{tabular}{llll}
\hline & Exp. (ref. 67) & DFT & ReaxFF \\
\hline $\mathrm{Cu}-\mathrm{O}$ & 1.91 & 1.95 & 1.98 \\
$\mathrm{C} 1-\mathrm{O}$ & 1.27 & 1.28 & 1.43 \\
$\mathrm{C} 1-\mathrm{C} 2$ & 1.39 & 1.40 & 1.40 \\
$\mathrm{C} 1-\mathrm{C} 3$ & 1.48 & 1.51 & 1.52 \\
$\angle \mathrm{Cu}-\mathrm{O}-\mathrm{C} 1$ & 125.9 & 126.0 & 127.9 \\
$\angle \mathrm{O}-\mathrm{C} 1-\mathrm{C} 3$ & 114.4 & 115.3 & 119.2 \\
$\angle \mathrm{O}-\mathrm{C} 1-\mathrm{C} 2$ & 124.4 & 125.4 & 126.8 \\
$\angle \mathrm{O}-\mathrm{Cu}-\mathrm{O}$ & 93.2 & 92.5 & 89.7
\end{tabular}


the surface, corresponding to a coverage of $\sim 0.4$ molecule $\mathrm{nm}^{-2}$. Above the adsorbed $\mathrm{Cu}(\mathrm{acac})_{2}, 2000 \mathrm{H}_{2} \mathrm{O}$ molecules or $\mathrm{H}$ atoms, or $1000 \mathrm{O}_{3}$ molecules were distributed randomly, with a density of $0.08 \mathrm{~g} \mathrm{~cm}^{-3}, 0.004 \mathrm{~g} \mathrm{~cm}^{-3}$, and $0.1 \mathrm{~g} \mathrm{~cm}^{-3}$, respectively. We used a relatively high density of co-reactants to ensure sufficient reactivity of the system and hence to obtain results within a reasonable calculation time.

\section{Results and discussion}

\section{Adsorption and dissociation of $\mathrm{Cu}(\mathrm{acac})_{2}$ on the surface}

In the first part of our study on copper precursors we analyze the surface adsorption and succeeding dissociation of the precursors on various surfaces. The adsorption of $\mathrm{Cu}(\mathrm{acac})_{2}$ on $\mathrm{Cu}$ is studied in detail before we compare these findings to those on other surfaces. On the $\mathrm{Cu}(110)$ surface we consider four different adsorption sites: top (T), hollow (H), bridge1 (B1) and bridge2 (B2) (see Fig. 2a). For each position, different adsorption orientations of species were examined. The calculated adsorption energies and structures of $\mathrm{Cu}(\mathrm{acac})_{2}$ and its dissociation products are presented in Table 2 and Fig. 2. As depicted in Fig. 2b-d, three stable configurations have been obtained for the adsorption of $\mathrm{Cu}(\mathrm{acac})_{2}$. On the top and bridge1 sites, $\mathrm{Cu}(\mathrm{acac})_{2}$ prefers to adsorb on $\mathrm{Cu}(110)$ with a parallel orientation (Fig. 2b and c). Geometric parameters of the adsorbed $\mathrm{Cu}(\mathrm{acac})_{2}$ are barely changed relative to a gaseous molecule (not shown here). The adsorption energies computed by using the PBE functional are $-0.48 \mathrm{eV}$ for top and $-0.33 \mathrm{eV}$ for bridge2, respectively (Table 2). It is well known that the pure GGA-PBE does not capture van der Waals forces (dispersion forces), leading to an underestimated binding energy. ${ }^{56}$ Indeed, the vdW-DF functional predicts much higher adsorption energies $(-1.42 \mathrm{eV}$ and $-1.34 \mathrm{eV})$, indicating that the $\mathrm{vdW}$ forces are the dominant interactions. One the other hand, $\mathrm{Cu}(\mathrm{acac})_{2}$ is found to strongly chemisorb on the hollow site with a binding energy of $-1.51 \mathrm{eV}$ for PBE (Table 2). The energy calculated using vdW-DF is $0.65 \mathrm{eV}$ larger than that using $\mathrm{PBE}$, because of the contribution of vdW forces between the acac-ligands and the surface. The $\mathrm{Cu}(\mathrm{acac})_{2}$ molecule is significantly distorted from planarity to
Table 2 Adsorption properties for different species on the $\mathrm{Cu}(110)$ surface $^{a}$

\begin{tabular}{|c|c|c|c|c|c|c|c|}
\hline & & \multicolumn{3}{|c|}{$\mathrm{Cu}(\mathrm{acac})_{2}$} & \multirow{2}{*}{$\begin{array}{l}\frac{\mathrm{Cu}(\mathrm{acac})}{\text { Hollow }} \\
\end{array}$} & \multirow{2}{*}{$\begin{array}{l}\text { acac } \\
\text { Top }\end{array}$} & \multirow{2}{*}{$\begin{array}{l}\mathrm{Cu} \\
\text { Hollow }\end{array}$} \\
\hline & $\begin{array}{l}\text { Adsorption } \\
\text { site }\end{array}$ & Top & Bridge1 & Hollow & & & \\
\hline \multirow[t]{3}{*}{$E_{\text {ads }}(\mathrm{eV})$} & PBE & -0.48 & -0.33 & -1.51 & -2.16 & -2.68 & -3.08 \\
\hline & vdW-DF & -1.42 & -1.34 & -2.16 & -2.08 & -2.89 & -2.81 \\
\hline & ReaxFF & -1.24 & -1.33 & -2.11 & -2.11 & -2.44 & -3.33 \\
\hline$d\left(\mathrm{Cu}_{\mathrm{p}^{-}}\right.$ & PBE & 2.65 & 2.76 & 2.63 & 2.62 & - & 2.53 \\
\hline \multirow[t]{2}{*}{$\left.\mathrm{Cu}_{\mathrm{s}}\right)(\AA)$} & vdW-DF & 2.70 & 2.90 & 2.68 & 2.63 & - & 2.59 \\
\hline & ReaxFF & 2.47 & 2.62 & 2.63 & 2.61 & - & 2.61 \\
\hline \multirow{3}{*}{$\begin{array}{l}d\left(\mathrm{Cu}_{\mathrm{p}}-\mathrm{O}\right) \\
(\AA)\end{array}$} & PBE & 2.04 & 2.02 & 2.21 & 2.00 & - & - \\
\hline & vdW-DF & 2.07 & 2.04 & 2.24 & 2.03 & - & - \\
\hline & ReaxFF & 2.01 & 2.02 & 2.88 & 1.97 & - & - \\
\hline \multirow{3}{*}{$\begin{array}{l}d\left(\mathrm{Cu}_{\mathrm{s}}-\mathrm{O}\right) \\
(\AA)\end{array}$} & PBE & 3.45 & 2.99 & 2.07 & 3.28 & 2.01 & - \\
\hline & vdW-DF & 3.52 & 3.13 & 2.14 & 3.33 & 2.08 & - \\
\hline & ReaxFF & 3.16 & 2.72 & 1.95 & 3.22 & 1.99 & - \\
\hline
\end{tabular}

${ }^{a} E_{\text {ads }}$ denotes the adsorption energy. $d\left(\mathrm{Cu}_{\mathrm{p}}-\mathrm{Cu}_{\mathrm{s}}\right)$ is the distance between the $\mathrm{Cu}$ atom of the precursor and nearest surface $\mathrm{Cu}$ atom. $d\left(\mathrm{Cu}_{\mathrm{p}}-\mathrm{O}\right)$ stands for the distance between the $\mathrm{Cu}$ and $\mathrm{O}$ atoms of the precursor. $d\left(\mathrm{Cu}_{\mathrm{s}}-\mathrm{O}\right)$ represents the distance between the $\mathrm{O}$ atom of the precursor or the acac-ligand and the nearest surface $\mathrm{Cu}$ atom. Only the most stable adsorption structures for the $\mathrm{Cu}(\mathrm{acac})$, acac, and $\mathrm{Cu}$ species are presented.

enhance adsorption (Fig. 2d). Four $\mathrm{Cu}-\mathrm{O}$ bonds are formed between the surface $\mathrm{Cu}$ atoms and $\mathrm{O}$ of $\mathrm{Cu}(\mathrm{acac})_{2}$, with a bond length of $2.07 \AA$. However, bond length of the original $\mathrm{Cu}-\mathrm{O}$ bond of $\mathrm{Cu}(\mathrm{acac})_{2}$ is increased from $1.95 \AA$ (in the gas-phase) to $2.21 \AA$ (on the surface), which weakens the $\mathrm{Cu}-\mathrm{O}$ bond strength. In contrast to $\mathrm{Cu}(\mathrm{acac})_{2}$ both $\mathrm{Cu}$ (acac) and acac prefer to adsorb with the molecular axis being perpendicular to the $\mathrm{Cu}$ surface normal (Fig. 2f and g). The most stable adsorption sites are the hollow $\left(E_{\mathrm{ads}}=-2.16 \mathrm{eV}\right.$ for $\left.\mathrm{PBE}\right)$ and top $\left(E_{\mathrm{ads}}=-2.68 \mathrm{eV}\right.$ for $\left.\mathrm{PBE}\right)$ sites, respectively (Table 2). The $\mathrm{Cu}$ atom prefers to adsorb on the hollow site, with a binding energy of $-3.08 \mathrm{eV}$ for the PBE functional. The vdW forces have no significant influence on the adsorption energy of $\mathrm{Cu}(\mathrm{acac})$, acac, and $\mathrm{Cu}$ species, suggesting that chemisorption is the dominant interaction.

In order to demonstrate the validity of our model calculations we have also performed vibrational frequency calculations and compared it with experimental findings. ${ }^{68}$ The perpendicular adsorption geometries of $\mathrm{Cu}(\mathrm{acac})$ and acac have been confirmed
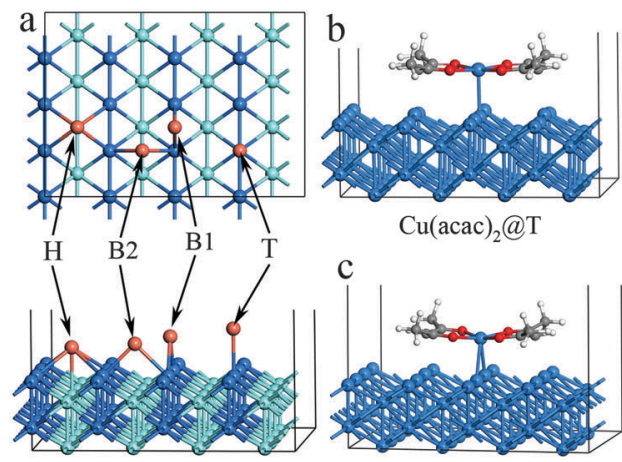

$\mathrm{Cu}(\mathrm{acac})_{2} @ \mathrm{~T}$

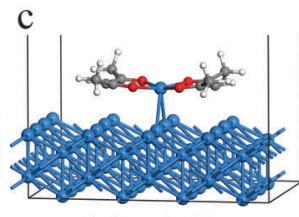

$\mathrm{Cu}(\mathrm{acac})_{2} @ \mathrm{~B} 1$

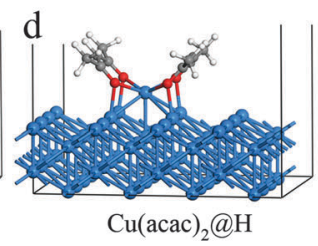

$\mathrm{e}$

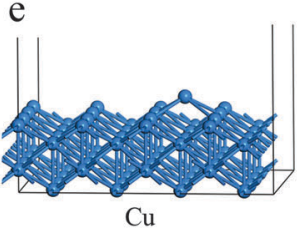

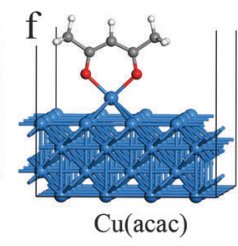

$\mathrm{g}$

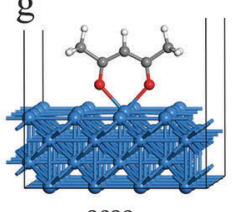

acac

Fig. 2 Adsorption sites (a) and optimized geometries of different adsorbed species $(b-g)$ on the Cu(110) surface calculated using the DFT-PBE functional. The adsorption geometries calculated using vdW-DF and ReaxFF are similar to that calculated using DFT-PBE and are thus not shown here. 
Table 3 The calculated and measured (from ref. 68 and 69) vibrational frequencies $\left(\mathrm{cm}^{-1}\right)$ of different species adsorption on the Cu surface

\begin{tabular}{|c|c|c|c|c|c|c|}
\hline $\mathrm{Cu}(\mathrm{acac})_{2} / \mathrm{Cu}(110)$ & $\mathrm{Cu}(\mathrm{acac}) / \mathrm{Cu}(110)$ & $\mathrm{acac} / \mathrm{Cu}(110)$ & $\mathrm{Cu}(\mathrm{acac})_{2}$ & acac/Cu(001) & $\mathrm{Cu}(\mathrm{acac})_{2}$ & \\
\hline 3060 & 3059 & 3077 & 3090 & 3092 & 3077 & Methyne $\mathrm{CH}$ stretch \\
\hline 1442 & 1450 & 1439 & 1434 & 1430 & 1415 & $\mathrm{CH}_{3}$ deg. def. \\
\hline 1367 & 1378 & 1374 & 1355 & & 1356 & $\mathrm{CH}_{3}$ sym. def. \\
\hline 1238 & 1238 & 1247 & 1249 & & 1274 & $\mathrm{CC}+\mathrm{CCH}_{3}$ stretch \\
\hline 1160 & 1199 & 1201 & 1172 & & 1190 & CH bending \\
\hline
\end{tabular}

Only the key vibrational frequencies are shown. The frequencies of acac/Cu(001) are very similar to that of acac/Cu(110), indicating that the orientation of the $\mathrm{Cu}$ surface has a minor effect on the normal modes of the acac-ligand.

by vibrational spectroscopy studies. As shown in Table 3, the key vibrational frequencies of adsorbed $\mathrm{Cu}(\mathrm{acac})$ and acac match well with that of gaseous $\mathrm{Cu}(\mathrm{acac})_{2}$, indicating that the surface acac-ligand maintains the same geometric configuration as the gaseous $\mathrm{Cu}(\mathrm{acac})_{2} \cdot{ }^{68,69}$ In contrast, frequency of the CO stretch of adsorbed $\mathrm{Cu}(\mathrm{acac})_{2}$ is shifted from $1556 \mathrm{~cm}^{-1}$ to $1507 \mathrm{~cm}^{-1}$ relative to gaseous $\mathrm{Cu}(\mathrm{acac})_{2}$. This is consistent with a parallel adsorption geometry causing a distorted molecular structure on the surface.

Table 2 also shows the comparison of adsorption energies and bond lengths between ReaxFF and as obtained from DFT. Since no benchmark data are currently available for the

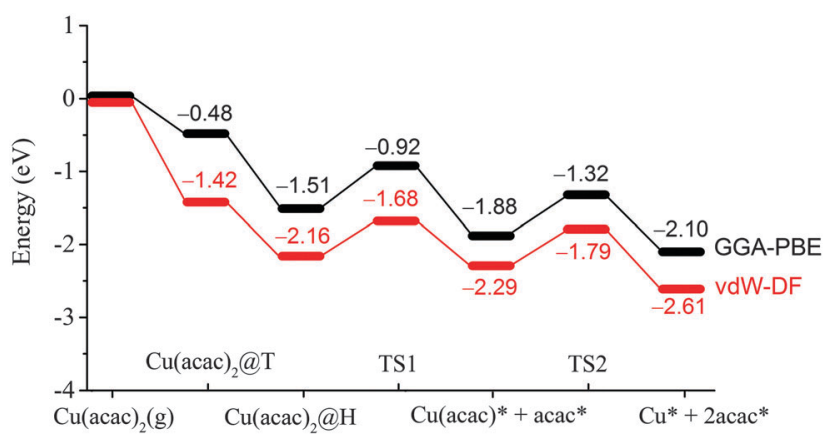

Fig. 3 Energy profile of the dissociation processes of $\mathrm{Cu}(\mathrm{acac})_{2}$ on the $\mathrm{Cu}(110)$ surface.
$\mathrm{Cu}(\mathrm{acac})_{2} / \mathrm{Cu}(110)$ system, we thus use the vdW-DF results as a reference to evaluate the accuracy of ReaxFF. Recent DFT calculations for a $\mathrm{Cu}(\mathrm{dmap})_{2} / \mathrm{Cu}(111)(\mathrm{dmap}=$ dimethylamino2-propoxide) system have found that the vdW interactions not only increase the adsorption energies but also change the nature of the adsorption fundamentally. ${ }^{46}$ It can be seen from Table 2 that most of the ReaxFF results match well with the DFT results. The average energetic discrepancies with respect to the vdW-DF are $\pm 0.22 \mathrm{eV}$ (8.9\%) and $\pm 0.18 \AA$ (6.9\%), respectively. The only exception is that ReaxFF fails to predict the structure for $\mathrm{Cu}(\mathrm{acac})_{2}$ adsorption on the hollow site. A large distance between $\mathrm{Cu}$ and $\mathrm{O}$ atoms $(2.88 \AA)$ is associated with the dissociative adsorption of $\mathrm{Cu}(\mathrm{acac})_{2}$ on the surface.

After the preferred adsorption geometries for different species were determined, the minimum energy pathway for $\mathrm{Cu}(\mathrm{acac})_{2}$ dissociation on the $\mathrm{Cu}$ surface was mapped out using the CI-NEB method, which is depicted in Fig. 3 and 4. The clean $\mathrm{Cu}(110)$ surface with a gaseous precursor is selected as the reference state, while $\mathrm{Cu}$ with co-adsorbed acac-ligands on the surface is set as the final state. In general, the decomposition of $\mathrm{Cu}(\mathrm{acac})_{2}$ on $\mathrm{Cu}(110)$ is an exothermic process. The calculated reaction energies for the whole process are $-2.10 \mathrm{eV}$ with $\mathrm{PBE}$ and $-2.61 \mathrm{eV}$ with vdW-DF, respectively. $\mathrm{Cu}(\mathrm{acac})_{2}$ can easily diffuse from the top or bridge1 site to the nearby lowest energy hollow site, with no appreciable energy barrier $(<0.1 \mathrm{eV})$. The dissociation of one acac-ligand from adsorbed $\mathrm{Cu}(\mathrm{acac})_{2}$ requires to overcome

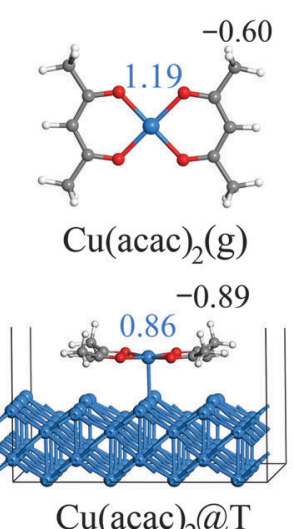

$\mathrm{Cu}(\mathrm{acac})_{2} @ \mathrm{~T}$

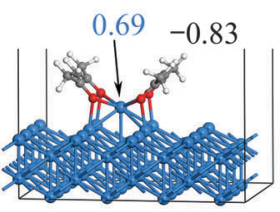

$\mathrm{Cu}(\mathrm{acac})_{2} @ \mathrm{H}$

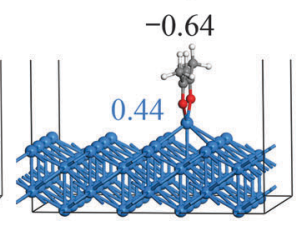

$\mathrm{Cu}(\mathrm{acac})$

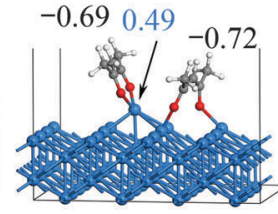

TS1

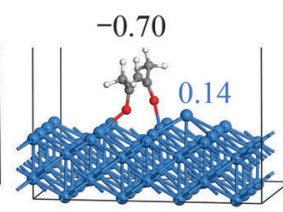

TS2
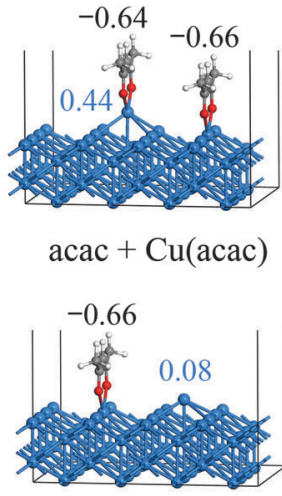

$\mathrm{acac}+\mathrm{Cu}$

Fig. 4 Geometric structures and Mulliken charge for the dissociation of $\mathrm{Cu}(\mathrm{acac})_{2}$ on the $\mathrm{Cu}(110)$ surface calculated using the DFT-PBE functional. Values shown in blue and black colors represent the charge of the $\mathrm{Cu}$ atom and the acac-ligand of the Cu precursor, respectively. 
energy barriers of $0.59 \mathrm{eV}$ for PBE and $0.48 \mathrm{eV}$ for vdW-DF, respectively. At the transition state, the acac-ligand is located above a hollow site, with two oxygen atoms bound to the adjacent surface $\mathrm{Cu}$ atoms (Fig. 4). Reaction barrier for the decomposition of $\mathrm{Cu}$ (acac) into $\mathrm{Cu}+$ acac is similar to that of $\mathrm{Cu}(\mathrm{acac})_{2}$, with $0.56 \mathrm{eV}$ for PBE and $0.50 \mathrm{eV}$ for vdW-DF, respectively. Again, the acac-ligand at the transition state is positioned above the hollow site. The population analysis shown in Fig. 4 suggests that adsorption of $\mathrm{Cu}(\mathrm{acac})_{2}$ and its further dissociation into $\mathrm{Cu}(\mathrm{acac})$ and $\mathrm{Cu}$ would lead to sequential reduction of the $\mathrm{Cu}$ center $(1.19 e \rightarrow 0.86 e \rightarrow 0.69 e \rightarrow 0.44 e \rightarrow 0.08 e)$. A zero-valence metallic $\mathrm{Cu}$ atom is formed finally. On the other hand, the acac-ligand of $\mathrm{Cu}(\mathrm{acac})_{2}$ is firstly reduced upon adsorption $(-0.60 e \rightarrow-0.83 e)$ and is then oxidized upon dissociation $(-0.83 e \rightarrow-0.66 e)$. Charge of the acac-ligand in the final state $(-0.66 e)$ is similar to that in the reference state $(-0.60 e)$, suggesting that the metallic substrate is responsible for the reduction of the $\mathrm{Cu}$ center of $\mathrm{Cu}(\mathrm{acac})_{2}$. In short, our DFT calculations reveal a sequential dissociation and reduction $\left[\mathrm{Cu}(\mathrm{acac})_{2} \rightarrow \mathrm{Cu}(\mathrm{acac}) \rightarrow \mathrm{Cu}\right]$ of the $\mathrm{Cu}$ precursor on the $\mathrm{Cu}(110)$ surface, which is in accordance with previous XPS investigations. ${ }^{29}$

In principle, the ligands are used to volatilize the metal atoms. Thus the ligands are expected to remain intact upon adsorption and will be removed by the co-reactant (e.g. hydrogen or oxygen) during the subsequent ALD half cycle. ${ }^{28}$ Table 4 lists the DFT-PBE calculated reaction energies for the further decomposition of the acac-ligand. The large positive energies reveal that the further decomposition of the acac-ligand on a $\mathrm{Cu}(110)$ surface is unfavorable. Thus, the stable acac-ligand may block surface sites and prevents the adsorption of further $\mathrm{Cu}$ precursor molecules, and therefore the deposition is self-limited.

The RMD simulation snapshots of the $\mathrm{Cu}(\mathrm{acac})_{2}$ decomposition on the $\mathrm{Cu}(110)$ surface at $600 \mathrm{~K}$ are shown in Fig. 5. In general, the reaction pathways observed in RMD simulations are consistent with those from the DFT calculations. The reaction starts by breaking of the $\mathrm{Cu}-\mathrm{O}$ bond and the tilt of the acacligand (7.3 ps). Next, the acac-ligand dissociates completely from the $\mathrm{Cu}(\mathrm{acac})_{2}$ molecule, forming acac and $\mathrm{Cu}$ (acac) species on the surface (10.8 ps). Finally, $\mathrm{Cu}(\mathrm{acac})$ dissociates into $\mathrm{Cu}$ and acac species on the surface after 18.5 ps. Experimentally, the complete decomposition of $\mathrm{Cu}(\mathrm{acac})_{2}$ to metallic $\mathrm{Cu}$ on the surface is reported to occur at around $300 \mathrm{~K}^{29}$ Such a low reaction temperature suggests a high reactivity of the $\mathrm{Cu}$ surface towards $\mathrm{Cu}(\mathrm{acac})_{2}$, which is consistent with the small activation energy calculated by DFT. In addition, a facile reaction process is also compatible with the time scale of the RMD simulations.

Table 4 DFT-PBE calculated reaction energies for the dissociation of the acac-ligand $\left(\mathrm{CH}_{3} \mathrm{COCHCOCH}\right)$ on the $\mathrm{Cu}(110)$ surface

\begin{tabular}{ll}
\hline Reaction & Energy (eV) \\
\hline acac $^{*} \rightarrow \mathrm{CH}_{3} \mathrm{CO}^{*}+\mathrm{CH}_{3} \mathrm{COCH}^{*}$ & 1.69 \\
acac$^{*} \rightarrow \mathrm{CH}_{3}^{*}+\mathrm{CH}_{3} \mathrm{COCHCO}^{*}$ & 2.14 \\
acac$^{*} \rightarrow 2 \mathrm{CH}_{3} \mathrm{CO}^{*}+\mathrm{CH}^{*}$ & 3.03 \\
acac$^{*} \rightarrow \mathrm{CH}_{3}^{*}+\mathrm{CO}^{*}+\mathrm{CH}_{3} \mathrm{COCH}^{*}$ & 2.01 \\
acac $^{*} \rightarrow 2 \mathrm{CH}_{3}^{*}+2 \mathrm{CO}^{*}+\mathrm{CH}^{*}$ & 3.66
\end{tabular}

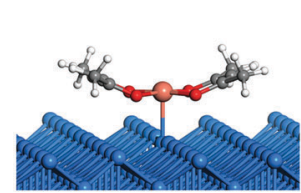

Initial state

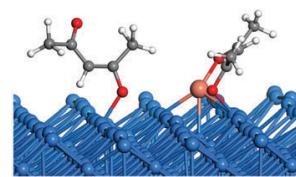

$10.8 \mathrm{ps}$

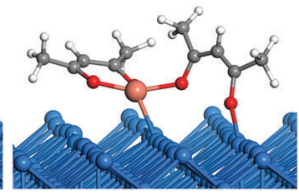

$7.3 \mathrm{ps}$

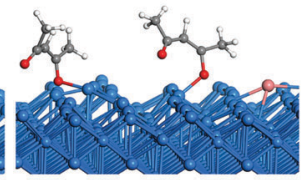

$18.5 \mathrm{ps}$
Fig. 5 RMD snapshots for the dissociation of $\mathrm{Cu}(\mathrm{acac})_{2}$ on the $\mathrm{Cu}(110)$ surface.

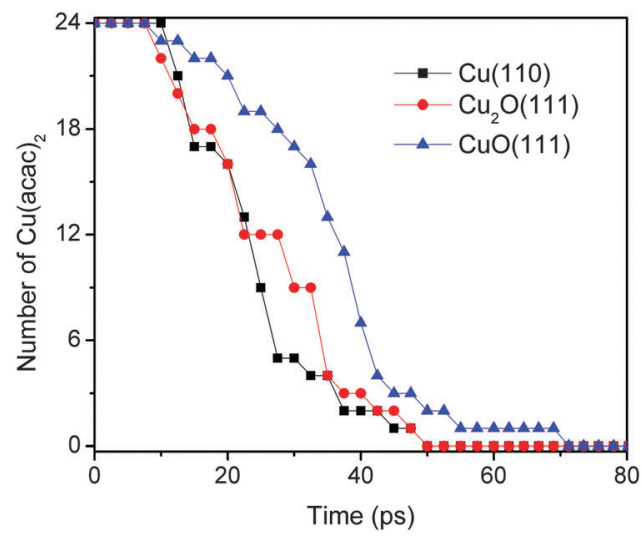

Fig. 6 Comparison of the dissociation of $\mathrm{Cu}(\mathrm{acac})_{2}$ into $\mathrm{Cu}(\mathrm{acac})$ and acac on $\mathrm{Cu}(110), \mathrm{Cu}_{2} \mathrm{O}(111)$, and $\mathrm{CuO}(111)$ surfaces at $600 \mathrm{~K}$.

Fig. 6 shows the comparison for $\mathrm{Cu}(\mathrm{acac})_{2}$ dissociation into $\mathrm{Cu}$ (acac) and acac on $\mathrm{Cu}(110), \mathrm{Cu}_{2} \mathrm{O}(111)$, and $\mathrm{CuO}(111)$ surfaces. Initially, $24 \mathrm{Cu}(\mathrm{acac})_{2}$ precursors were placed above the surface. The pathways of $\mathrm{Cu}(\mathrm{acac})_{2}$ dissociation on various substrates are similar, and are thus not shown here. As illustrated in Fig. 6, the $\mathrm{Cu}(\mathrm{acac})_{2}$ molecules are completely decomposed after $\sim 70 \mathrm{ps}$ at $600 \mathrm{~K}$. The reaction on copper-rich surfaces $[\mathrm{Cu}(110)$ and $\left.\mathrm{Cu}_{2} \mathrm{O}(111)\right]$ is faster as compared with that on $\mathrm{CuO}(111)$, indicating that surface $\mathrm{Cu}$ atoms are the reactive species towards the acac-ligand.

\section{Surface reaction between $\mathrm{Cu}(\text { acac })_{2}$ and different co-reactants}

In order to complement the picture of the surface reactions of $\mathrm{Cu}(\mathrm{acac})_{2}$ on various surfaces we analyze the role of different co-reactants which are typically used throughout ALD-processes. First, the reaction with molecular hydrogen is studied. Our RMD investigations reveal that molecular $\mathrm{H}_{2}$ hardly reacts with $\mathrm{Cu}(\mathrm{acac})_{2}$ on the surface at $600 \mathrm{~K}$. Instead, the molecules are found to assemble around the precursor, having weak attractive but nonbonded interactions with the structure. Therefore, we do not consider $\mathrm{H}_{2}$ molecules in our further studies. Indeed, molecular $\mathrm{H}_{2}$ is rarely employed as a co-reactant for $\mathrm{Cu} \beta$-diketonates. ${ }^{21}$ Alternatively, a plasma-enhanced ALD process ${ }^{20,21}$ or a strong reducing agent $\mathrm{t}^{8,23}$ is required to deposit the $\mathrm{Cu}$ thin films directly. 


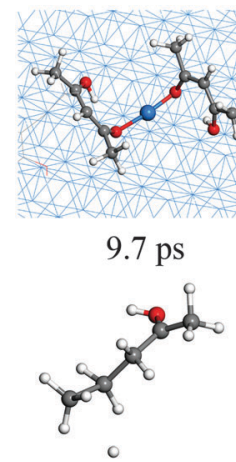

$20.1 \mathrm{ps}$

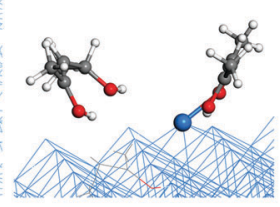

$14.6 \mathrm{ps}$

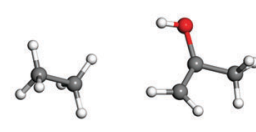

$20.3 \mathrm{ps}$

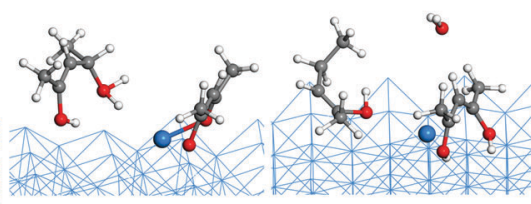

$14.7 \mathrm{ps}$

$15.2 \mathrm{ps}$

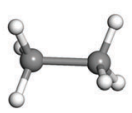

$22.2 \mathrm{ps}$

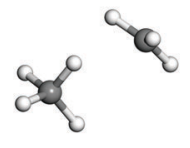

$22.4 \mathrm{ps}$

Fig. 7 RMD snapshots for the reaction between $\mathrm{Cu}(\mathrm{acac})_{2}$ and $\mathrm{H}$ atoms on the $\mathrm{Cu}(110)$ surface.

We now discuss the surface reaction between $\mathrm{Cu}(\mathrm{acac})_{2}$ and atomic $\mathrm{H}$ on $\mathrm{Cu}(110)$, as a model system for plasma enhanced $\mathrm{Cu}$ ALD. The corresponding typical RMD snapshots are shown in Fig. 7. The influence of other plasma-generated components (e.g., charged particles, electric fields, and heat $)^{22}$ is not considered in our simulation. In contrast to the molecular species, atomic hydrogen is found to be very reactive towards the $\mathrm{Cu}$ precursor. $\mathrm{Cu}(\mathrm{acac})_{2}$ breaks the $\mathrm{Cu}-\mathrm{O}$ bonds upon hydrogen impact, and a $\mathrm{H}_{2}$ (acac) molecule is formed and released to the gas-phase (14.6 ps). Next, an oxygen atom in $\mathrm{H}_{2}(\mathrm{acac})$ is abstracted by the hydrogen and a water molecule is released $(15.2 \mathrm{ps})$. The remaining fragment is dissociated further into ethane and acetone (20.3 ps). Finally, a methane molecule is produced $(22.4 \mathrm{ps})$. The time evolution of the species in the gasphase during the RMD simulations is shown in Fig. 8a. The formation of $\mathrm{H}_{x} \mathrm{O}$ species starts slightly earlier ( $\left.\sim 10 \mathrm{ps}\right)$ than that of $\mathrm{C}_{x} \mathrm{H}_{y}$ species, indicating that the atomic hydrogen reacts first with the oxygen of the $\mathrm{Cu}$ precursor. The system achieves the equilibrium after about $150 \mathrm{ps}$, in which the atomic hydrogen is consumed completely by the formation of $\mathrm{H}_{2}, \mathrm{C}_{x} \mathrm{H}_{y}$ and $\mathrm{H}_{x} \mathrm{O}$ species. Due to the re-adsorption of $\mathrm{H}_{x} \mathrm{O}$ species the amounts of surface $\mathrm{H}$ and $\mathrm{O}$ are slightly increased after $\sim 80$ ps. The $\mathrm{H}_{x} \mathrm{O}$ species exist mainly as $\mathrm{H}_{2} \mathrm{O}$ on the surface since the observed $\mathrm{H} / \mathrm{O}$ ratio is equal to $\sim 2$ (Fig. $8 \mathrm{~b}$ ). In contrast to the $\mathrm{H}$ and $\mathrm{O}$ containing species most of the $\mathrm{C}$ atoms are released to the gas-phase.

In the next part of this section we analyze the surface reactions between $\mathrm{Cu}(\mathrm{acac})_{2}$ and $\mathrm{H}_{2} \mathrm{O}$, as shown in Fig. 9. We use $\mathrm{Cu}_{2} \mathrm{O}(111)$ as the substrate since $\mathrm{Cu} \beta$-diketonates with $\mathrm{H}_{2} \mathrm{O}$ primarily deposit cuprous oxide films at low temperatures. ${ }^{9,70,71}$ Previous reports ${ }^{72,73}$ have shown that water facilitates the deposition of $\mathrm{Cu}_{2} \mathrm{O}$ through the following ligand-exchange reaction

$$
\mathrm{Cu}(\text { acac })+\mathrm{H}_{2} \mathrm{O} \rightarrow \mathrm{CuOH}+\mathrm{H}(\text { acac })
$$

Our RMD simulations predict the following reaction scheme which is consistent with previous findings. Firstly, $\mathrm{Cu}(\mathrm{acac})_{2}$ dissociates into $\mathrm{Cu}(\mathrm{acac})$ and acac on the surface after $\sim 25 \mathrm{ps}$ of simulation. Secondly, a proton is transferred from water to the adsorbed $\mathrm{Cu}(\mathrm{acac})$, forming $\mathrm{Cu}[\mathrm{H}(\mathrm{acac})]$ and $\mathrm{OH}$ species on the surface (56.8 ps). Finally, the $\mathrm{Cu}-\mathrm{O}$ bond of the $\mathrm{Cu}[\mathrm{H}(\mathrm{acac})]$ intermediate is then broken after $118.6 \mathrm{ps}$, which leads to the desorption of acetylacetone from the surface to the gas-phase. A similar ligand-exchange mechanism has been widely observed in water-based metal oxide ALD, for example, in the TMA- $\mathrm{H}_{2} \mathrm{O}$ $(\mathrm{TMA}=$ trimethylaluminum $)$ or $\mathrm{Hf}\left(\mathrm{NMe}_{2}\right)_{4}-\mathrm{H}_{2} \mathrm{O}\left(\mathrm{Me}=\mathrm{CH}_{3}\right)$ process. ${ }^{5,45}$ During the water pulse, the adsorbed Me- or $\mathrm{NMe}_{2}-$ ligands are replaced by - $\mathrm{OH}$ groups, followed by the elimination of gaseous $\mathrm{CH}_{4}$ or $\mathrm{HNMe}_{2} \cdot{ }^{5,45}$ It is noticed that cleavage of the $\mathrm{Cu}-\mathrm{O}$ bond of $\mathrm{Cu}(\mathrm{acac})_{2}$ in the presence of atomic $\mathrm{H}$ is promoted upon $\mathrm{H}$ impact, whereas with water the proton transition takes place after $\mathrm{Cu}(\mathrm{acac})_{2}$ is completely dissociated on the surface. These observations suggest that water is much less reactive compared to the atomic H. As shown in Fig. 8c, it can be found that $\mathrm{H}(\mathrm{acac})$ is the main gaseous product during this reaction, while the amounts of acac and $\mathrm{H}_{2}(\mathrm{acac})$ are minor. The surface reaction between $\mathrm{H}_{2} \mathrm{O}$ and the acac-ligand reaches stationary equilibrium after about $400 \mathrm{ps}$, in which about $35-40 \%$ of the acac-ligands are released to the gas-phase.

Typical RMD snapshots for the surface reactions between $\mathrm{Cu}(\text { acac })_{2}$ and $\mathrm{O}_{3}$ are shown in Fig. 10 and 11. The $\mathrm{CuO}(111)$ surface is used in these simulations, which is in line with the experimental observation that $\mathrm{CuO}$ is deposited by a $\mathrm{Cu}(\mathrm{acac})_{2}-$ $\mathrm{O}_{3}$ ALD process. ${ }^{11}$ As depicted in Fig. 10, the ozone molecule is found to bind readily with the methyl group through a hydrogen bond, forming an $\mathrm{O}-\mathrm{H}$ bond with a length of $\sim 1.9 \AA$ (Fig. 10a). One $\mathrm{H}$ atom of the acac-ligand is then abstracted by the ozone, as a result of the $\mathrm{OH}$ and $\mathrm{O}_{2}$ formation (16.8 ps). The released $\mathrm{OH}$ radical either re-adsorbs on the surface or reacts with methyl hydrogen to produce $\mathrm{H}_{2} \mathrm{O}$ (99.4 ps). Moreover, we observed that the $\mathrm{O}$ atom can insert into the $\mathrm{C}-\mathrm{H}$ bond of the $-\mathrm{CH}_{3}$ group, which involves the formation of $\mathrm{O}_{2}$ and $-\mathrm{CH}_{2} \mathrm{OH}$ species (94.3 ps). A similar insertion step has been reported to occur in the TMA- $\mathrm{O}_{3}$ ALD process, proven by infrared spectroscopy and DFT calculations. ${ }^{47,74,75}$ In comparison to the hydrogen abstraction, the $\mathrm{C}-\mathrm{C}$ cleavage usually takes place later. As shown in Fig. 11a-c, an oxygen atom firstly adsorbs above the bridging $\mathrm{C}-\mathrm{C}$ site to form an epoxide $(92.2 \mathrm{ps})$. The $\mathrm{C}-\mathrm{C}$ bond is then cleaved by the $\mathrm{O}$ atom through an epoxy-ether transformation (93.2 ps). At the same time, the acac-ligand breaks the bond with the surface $\mathrm{Cu}$ and is thus released to the gas-phase. Subsequently, the formed complex dissociates into the gaseous methylglyoxal, 

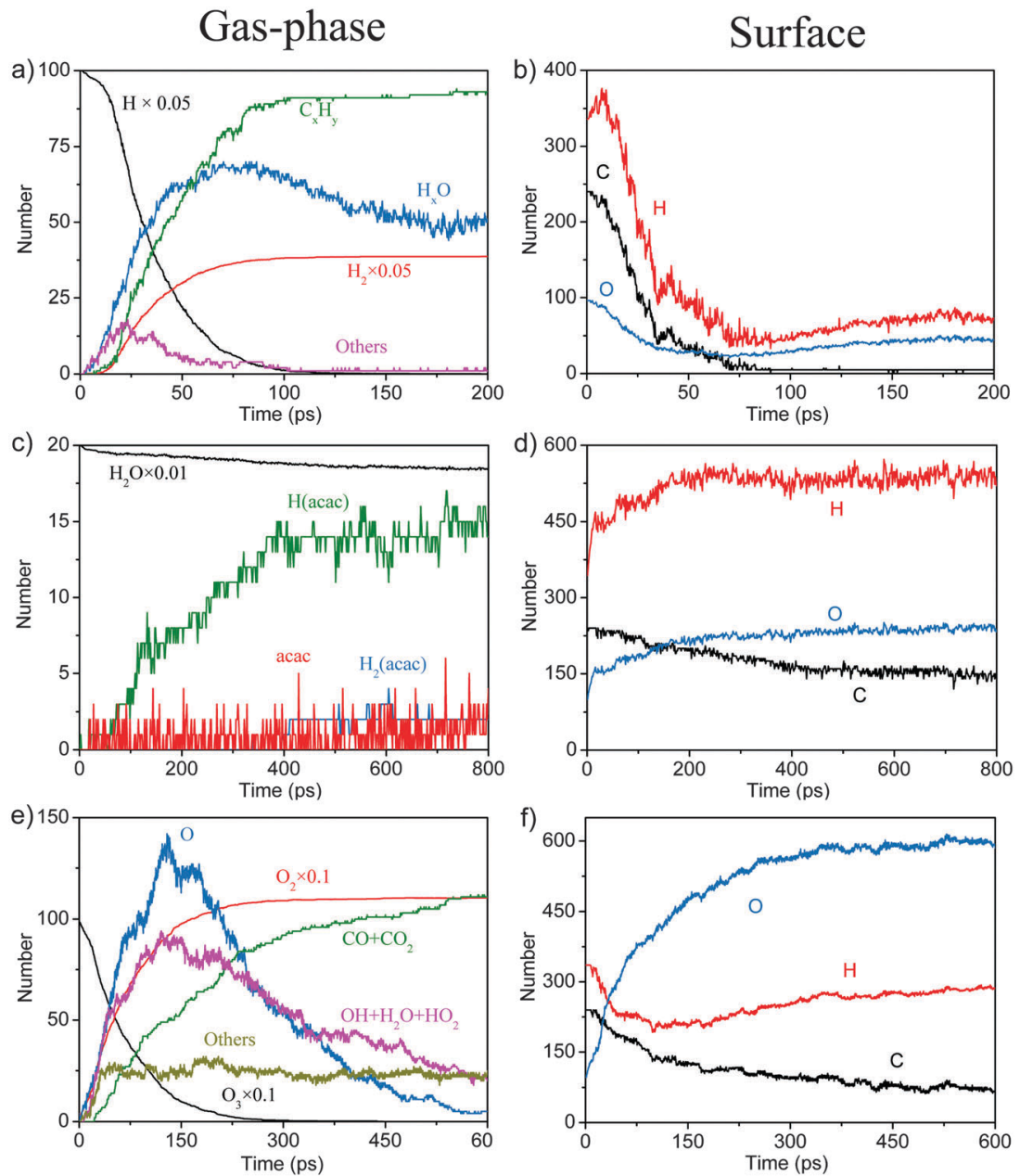

Fig. 8 Product evolution for the surface reactions between $\mathrm{Cu}(\mathrm{acac})_{2}$ and atomic $\mathrm{H}$ (a and b), water (c and d), and ozone (e and f), respectively.
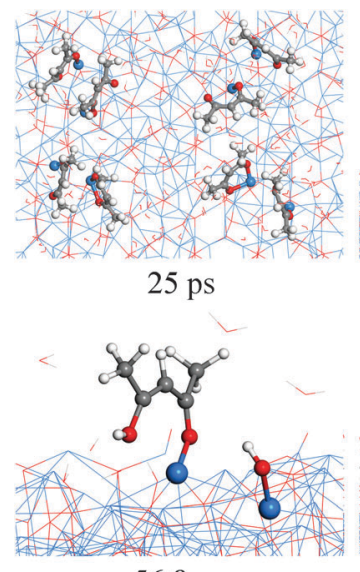

$56.8 \mathrm{ps}$

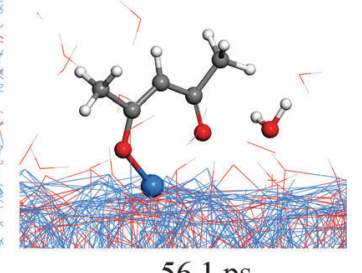

$56.1 \mathrm{ps}$

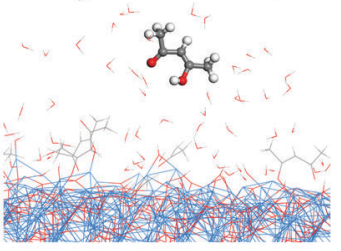

$118.6 \mathrm{ps}$

Fig. 9 RMD snapshots for the reaction between $\mathrm{Cu}(\mathrm{acac})_{2}$ and $\mathrm{H}_{2} \mathrm{O}$ on the $\mathrm{Cu}_{2} \mathrm{O}(111)$ surface.

ethenone, and an adsorbed hydroxyl group (93.8 ps). At last, the methylglyoxal and ethenone species are further oxidized into $\mathrm{CO}, \mathrm{CO}_{2}$ and $\mathrm{OH}$ after about 80 ps of simulation (not shown here). Fig. 11d-h illustrate the alternative reaction pathways for

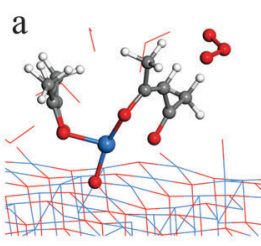

$16.4 \mathrm{ps}$

d

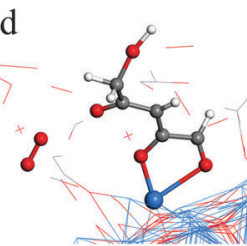

$94.3 \mathrm{ps}$

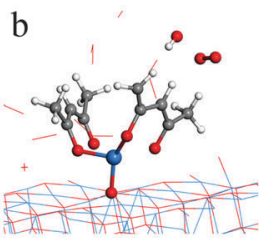

$16.8 \mathrm{ps}$

e

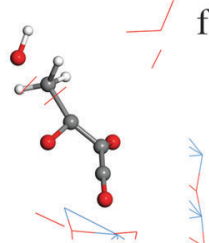

$98.3 \mathrm{ps}$

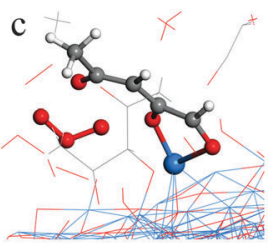

$93.9 \mathrm{ps}$

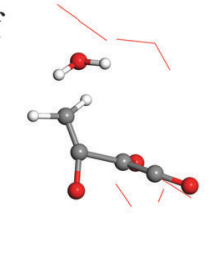

$99.4 \mathrm{ps}$
Fig. 10 RMD snapshots for $\mathrm{H}$ abstraction ( $a$ and b), $\mathrm{O}$ insertion ( $c$ and d), water formation (e and f) observed during the reaction between $\mathrm{Cu}(\mathrm{acac})_{2}$ and ozone on the $\mathrm{CuO}(111)$ surface.

C-C cleavage. Upon continuous adsorption of two $\mathrm{O}$ atoms, the acac-ligand dissociates into gaseous methylglyoxal and adsorbed acetate. The formed acetate is readily desorbed from the surface 


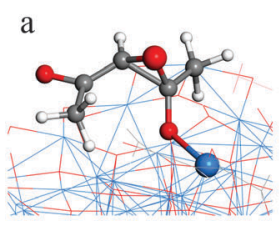

$92.2 \mathrm{ps}$

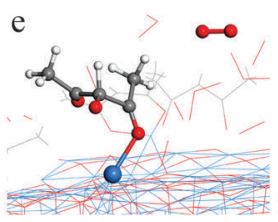

$70.2 \mathrm{ps}$

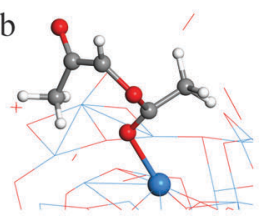

$93.2 \mathrm{ps}$

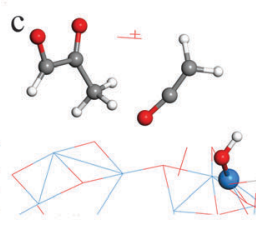

$93.8 \mathrm{ps}$

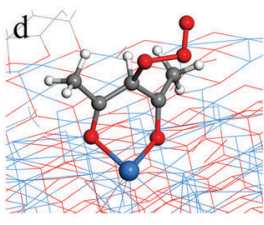

$69.7 \mathrm{ps}$

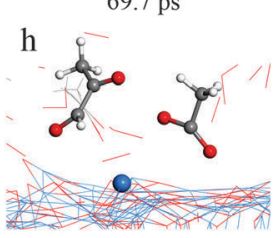

$147.6 \mathrm{ps}$

Fig. 11 RMD snapshots for $\mathrm{C}-\mathrm{C}$ breaking observed during the reaction between $\mathrm{Cu}(\mathrm{acac})_{2}$ and ozone on the $\mathrm{CuO}(111)$ surface.

and dissociates into $\mathrm{CO}_{2}$ and $\mathrm{CH}_{3}$. From the time evolution of species shown in Fig. 8e, it is found that most of the $\mathrm{O}_{3}$ is converted into $\mathrm{O}_{2}$ after $\sim 180 \mathrm{ps}$ upon either a surface reaction or self-dissociation in the gas-phase. The $\mathrm{H}_{x} \mathrm{O}_{y}$ and $\mathrm{CO}_{x}$ species are found to be the main by-products, suggesting a combustion-like reaction mechanism. This observation is consistent with previous in situ mass spectroscopy studies for a $\operatorname{Ir}(\mathrm{acac})_{3}-\mathrm{O}_{3} \mathrm{ALD}$ process. ${ }^{37}$ We have found that the evolution of $\mathrm{H}_{x} \mathrm{O}_{y}$ is about $\sim 10$ ps earlier than that of $\mathrm{CO}_{x}$ species, revealing that ozone reacts first with the hydrogen of the $\mathrm{Cu}$ precursor. Concentrations of the $\mathrm{H}$ species in the gas-phase increase firstly and decrease after $80 \mathrm{ps}$. At the equilibrium state, about $70 \%$ of the surface $\mathrm{C}$ impurities are released to the gas-phase, whereas the amount of surface $\mathrm{O}$ increases significantly after the $\mathrm{O}_{3}$ pulse (Fig. 8f). Most of the gaseous $\mathrm{H}_{x} \mathrm{O}_{y}$ are re-adsorbed on the surface, thus protons are available for the ligand-exchange reaction during the $\mathrm{Cu}(\mathrm{acac})_{2}$ pulse, as in the case of the $\mathrm{Cu}(\mathrm{acac})_{2}-\mathrm{H}_{2} \mathrm{O}$ process.

By comparison with the reaction rate and the carbon removal ratio under different conditions, it can be concluded that the reactivity of the co-reactants towards $\mathrm{Cu}(\mathrm{acac})_{2}$ follows the order $\mathrm{H}>\mathrm{O}_{3}>\mathrm{H}_{2} \mathrm{O}$. In experiment, it is well known that reactivity of the co-reactant has a large effect on an ALD temperature window. The lower bound of the ALD window is mainly determined by the thermal activation of a surface reaction as well as by the volatility of the precursor. ${ }^{5}$ Therefore, the ALD window could be used as an indicator to evaluate the reactivity between $\mathrm{Cu}(\mathrm{acac})_{2}$ and different co-reactants. A lower ALD window is associated with the higher reactivity of the co-reactant. As reported in the literature, when the $\mathrm{H}$ plasma is used for $\mathrm{Cu}(\mathrm{acac})_{2}$, the ALD window is as low as $85-135{ }^{\circ} \mathrm{C}^{21}$ However, much higher temperatures are required when ozone $\left(150-230{ }^{\circ} \mathrm{C}\right)^{11}$ or water $\left(210-300{ }^{\circ} \mathrm{C}\right)^{76}$ is used as the co-reactant. These results may suggest that the plasma $\mathrm{H}$ is more reactive towards $\mathrm{Cu}(\mathrm{acac})_{2}$ as compared to ozone and water, which is consistent with our conclusion.

\section{Conclusions}

In conclusion, the initial surface reactions of the $\mathrm{Cu}(\mathrm{acac})_{2}$ precursor during ALD were studied through DFT calculations and $\mathrm{RMD}$ simulations. The $\mathrm{Cu}(\mathrm{acac})_{2}, \mathrm{Cu}(\mathrm{acac})$ and $\mathrm{Cu}$ species prefer to adsorb on a hollow site, whereas the acac-ligand favors adsorption on the top site of the $\mathrm{Cu}(110)$ surface. The adsorption energies calculated by ReaxFF agree well with those calculated by vdW-DF. $\mathrm{Cu}(\mathrm{acac})_{2}$ is easily decomposed into a $\mathrm{Cu}$ atom and acac-ligands on the $\mathrm{Cu}(110)$ surface. The largest reaction barriers calculated using PBE and vdW-DF functionals are $0.59 \mathrm{eV}$ and $0.55 \mathrm{eV}$, respectively. Mulliken analysis reveals a sequential reduction of the $\mathrm{Cu}$ atom during the dissociation of $\mathrm{Cu}(\mathrm{acac})_{2}$ on $\mathrm{Cu}(110)$. The dissociated acac-ligands may act as site blockers for additional adsorption of the precursors, since they are thermodynamically stable on the surface. The RMD simulations imply that the decomposition pathways of $\mathrm{Cu}(\mathrm{acac})_{2}$ on various substrates are similar, but the copper-rich surfaces $\left[\mathrm{Cu}(110)\right.$ and $\left.\mathrm{Cu}_{2} \mathrm{O}(111)\right]$ are more reactive as compared with the $\mathrm{CuO}(111)$ surface. Mechanisms for the surface reaction between $\mathrm{Cu}(\mathrm{acac})_{2}$ and different co-reactants are also examined. The molecular hydrogen is found to be nonreactive towards the $\mathrm{Cu}$ precursor; whereas atomic $\mathrm{H}$ or water can remove the surface acacligands efficiently. The $\mathrm{H}$ atoms continuously impact with the $\mathrm{Cu}$ precursor, which lead to the breaking of $\mathrm{Cu}-\mathrm{O}, \mathrm{C}-\mathrm{O}$, and $\mathrm{C}-\mathrm{C}$ bonds sequentially. On the other hand, water reacts with the $\mathrm{Cu}(\mathrm{acac})_{2}$ on $\mathrm{Cu}_{2} \mathrm{O}(111)$ through a ligand-exchange reaction, producing the gaseous $\mathrm{H}(\mathrm{acac})$ and surface $\mathrm{OH}$ species. A combustion reaction with $\mathrm{CO}_{2}$ and $\mathrm{H}_{2} \mathrm{O}$ as the main byproducts is observed when adsorbed $\mathrm{Cu}(\mathrm{acac})_{2}$ reacts with ozone. Once equilibrium is reached, most of the gaseous $\mathrm{H}_{x} \mathrm{O}_{y}$ are re-adsorbed on the surface. Thus protons are available for the next ALD half cycle.

\section{Acknowledgements}

This work was supported by the German Research Foundation (DFG) in the International Research Training Group (IRTG), Project GRK-1215 "Materials and Concepts for Advanced Interconnects".

\section{References}

1 R. Rosenberg, D. C. Edelstein, C.-K. Hu and K. P. Rodbell, Annu. Rev. Mater. Sci., 2000, 30, 229-262.

2 R. Solanki and B. Pathangey, Electrochem. Solid-State Lett., 2000, 3, 479-480. 
3 Y. Sakamoto, K. Kamada, J. Hamaguchi, A. Sano, Y. Numata, S. Kodaira, S. Toyoda and K. Suu, Jpn. J. Appl. Phys., 2011, 50, 05EA03.

4 S. M. George, Chem. Rev., 2010, 110, 111-131.

5 R. L. Puurunen, J. Appl. Phys., 2005, 97, 121301.

6 T. J. Knisley, L. C. Kalutarage and C. H. Winter, Coord. Chem. Rev., 2013, 257, 3222-3231.

7 K. H. Park and W. J. Marshall, J. Am. Chem. Soc., 2005, 127, 9330-9331.

8 B. H. Lee, J. K. Hwang, J. W. Nam, S. U. Lee, J. T. Kim, S.-M. Koo, A. Baunemann, R. A. Fischer and M. M. Sung, Angew. Chem., Int. Ed., 2009, 48, 4536-4539.

9 T. Waechtler, S. Oswald, N. Roth, A. Jako, H. Lang, R. Ecke, S. E. Schulz, T. Gessner, A. Moskvinova, S. Schulze and M. Hietscholde, J. Electrochem. Soc., 2009, 156, H453-H459.

10 T. Waechtler, S. F. Ding, L. Hofmann, R. Mothes, Q. Xie, S. Oswald, C. Detavernier, S. E. Schulz, X. P. Qu, H. Lang and T. Gessner, Microelectron. Eng., 2011, 88, 684-689.

11 M. E. Alnes, E. Monakhov, H. Fjellvag and O. Nilsen, Chem. Vap. Deposition, 2012, 18, 173-178.

12 B. S. Lim, A. Rahtu and R. G. Gordon, Nat. Mater., 2003, 2, 749-754.

13 Z. Li, S. T. Barry and R. G. Gordon, Inorg. Chem., 2005, 44, 1728-1735.

14 J. W. Park, H. S. Jang, M. Kim, K. Sung, S. S. Lee, T. Chung, S. Koo, C. G. Kim and Y. Kim, Inorg. Chem. Commun., 2004, 7, 463-466.

15 J. P. Coyle, W. H. Monillas, G. P. A. Yap and S. T. Barry, Inorg. Chem., 2008, 47, 683-689.

16 A. M. Willcocks, T. P. Robinson, R. Roche, T. Pugh, S. P. Richards, A. J. Kingsley, J. P. Lowe and A. L. Johnson, Inorg. Chem., 2012, 51, 246-257.

17 J. P. Coyle, A. Kurek, P. J. Pallister, E. R. Sirianni, G. P. A. Yap and S. T. Barry, Chem. Commun., 2012, 48, 10440-10442.

18 T. Kim, Y. Yao, J. P. Coyle, S. T. Barry and F. Zaera, Chem. Mater., 2013, 25, 3630-3639.

19 M. Utriainen, M. Kröger-Laukkanen, L. S. Johansson and L. Niinistö, Appl. Surf. Sci., 2000, 157, 151-158.

20 A. Niskanen, A. Rahtu, T. Sajavaara, K. Arstila, M. Ritala and M. Leskelä, J. Electrochem. Soc., 2005, 152, G25-G28.

21 L. Wu and E. Eisenbraun, J. Vac. Sci. Technol., B, 2007, 25, 2581-2585.

22 H. B. Profijt, S. E. Potts, M. C. M. Van de Sanden and W. M. M. Kessels, J. Vac. Sci. Technol., A, 2011, 29, 050801.

23 T. J. Knisley, T. C. Ariyasena, T. Sajavaara, M. J. Saly and C. H. Winter, Chem. Mater., 2011, 23, 4417-4419.

24 G. Dey and S. D. Elliott, RSC Adv., 2014, 4, 34448-34453.

25 J. M. Park, K. Jin, B. Han, M. J. Kim, J. Jung, J. J. Kim and W. J. Lee, Thin Solid Films, 2014, 556, 434-439.

26 D. Dhakal, T. Waechtler, S. E. Schulz, T. Gessner, H. Lang, R. Mothes and A. Tuchscherer, J. Vac. Sci. Technol., A, 2014, 32, 041505.

27 D. Dhakal, T. Waechtler, S. E. Schulz, S. Moeckel, H. Lang and T. Gessner, 2nd International Conference on ALD Applications \& 3rd China ALD conference, Shanghai, 2014.

28 F. Zaera, J. Phys. Chem. Lett., 2012, 3, 1301-1309.
29 Q. Ma and F. Zaera, J. Vac. Sci. Technol., A, 2013, 31, $01 \mathrm{~A} 112$. 30 S. D. Elliott, Semicond. Sci. Technol., 2012, 27, 074008.

31 G. Dey and S. D. Elliott, J. Phys. Chem. A, 2012, 116, 8893-8901. 32 J. Lin, A. V. Teplyakov and J. C. F. Rodrigues-Reyes, J. Vac. Sci. Technol., A, 2013, 31, 021401.

33 X. Hu, J. Schuster, S. E. Schulz and T. Gessner, Microelectron. Eng., 2015, 137, 23-31.

34 E. Machado, M. Kaczmarski, P. Ordejón, D. Garg, J. Norman and H. Cheng, Langmuir, 2005, 21, 7608-7614.

35 E. Machado, M. Kaczmarski, B. Braida, P. Ordejón, D. Garg, J. Norman and H. Cheng, J. Mol. Model., 2007, 13, 861-864. 36 G. Dey and S. D. Elliott, J. Phys. Chem. C, 2015, 119, 5914-5927.

37 G. Dey, J. S. Wrench, D. J. Hagen, L. Keeney and S. D. Elliott, Dalton Trans., 2015, 44, 10188-10199.

38 G. Dey and S. D. Elliott, Theor. Chem. Acc., 2014, 133, 1416. 39 L. Pirolli and A. V. Teplyakov, Surf. Sci., 2006, 600, 3313-3320. 40 P. Mårtensson, K. Larsson and J. O. Carlsson, Appl. Surf. Sci., 1998, 136, 137-146.

41 P. Mårtensson, K. Larsson and J. O. Carlsson, Appl. Surf. Sci., 1999, 148, 9-16.

42 P. Mårtensson, K. Larsson and J. O. Carlsson, Appl. Surf. Sci., 2000, 157, 92-100.

43 S. Chen, G. Fang, X. Qian, A. Li and J. Ma, J. Phys. Chem. C, 2011, 115, 23363-23373.

44 G. Fang, S. Chen, A. Li and J. Ma, J. Phys. Chem. C, 2012, 116, 26436-26448.

45 M. Shirazi and S. D. Elliott, Chem. Mater., 2013, 25, 878-889.

46 Y. Maimaiti and S. D. Elliott, J. Phys. Chem. C, 2015, 119, 9375-9385.

47 S. D. Elliott, G. Scarel, C. Wiemer, M. Fanciulli and G. Pavia, Chem. Mater., 2006, 18, 3764-3773.

48 L. Huang, B. Han, B. Han, A. Derecskei-Kovacs, M. Xiao, X. Lei, M. L. O’Neill, R. M. Pearlstein, H. Chandra and H. Cheng, J. Phys. Chem. C, 2013, 117, 19454-19463.

49 G. Fang, L. Xu, Y. Cao, L. Wang, D. Wu and A. Li, Chem. Commun., 2015, 51, 1341-1344.

50 A. C. T. van Duin, S. Dasgupta, F. Lorant and W. A. Goddard, J. Phys. Chem. A, 2001, 105, 9396-9409.

51 K. Knapas and M. Ritala, Chem. Mater., 2011, 23, 2766-2771. 52 P. Giannozzi, S. Baroni, N. Bonini, M. Calandra, R. Car, C. Cavazzoni, D. Ceresoli, G. L. Chiarotti, M. Cococcioni, I. Dabo, A. Dal Corso, S. de Gironcoli, S. Fabris, G. Fratesi, R. Gebauer, U. Gerstmann, C. Gougoussis, A. Kokalj, M. Lazzeri, L. Martin-Samos, N. Marzari, F. Mauri, R. Mazzarello, S. Paolini, A. Pasquarello, L. Paulatto, C. Sbraccia, S. Scandolo, G. Sclauzero, A. P. Seitsonen, A. Smogunov, P. Umari and R. M. Wentzcovitch, J. Phys.: Condens. Matter, 2009, 21, 395502.

53 J. P. Perdew, K. Burke and M. Ernzerhof, Phys. Rev. Lett., 1996, 77, 3865-3868.

54 D. Vanderbilt, Phys. Rev. B: Condens. Matter Mater. Phys., 1990, 41, 7892-7895.

55 H. J. Monkhorst and J. D. Pack, Phys. Rev. B: Solid State, 1976, 13, 5188.

56 M. Dion, H. Rydberg, E. Schroder, D. C. Langreth and B. I. Lundqvist, Phys. Rev. Lett., 2004, 92, 246401. 
57 S. Baroni, S. De Gironcoli, A. Dal Corso and P. Giannozzi, Rev. Mod. Phys., 2001, 73, 515-562.

58 G. Henkelman, B. P. Uberuaga and H. Jonsson, J. Chem. Phys., 2000, 113, 9901-9904.

59 G. Henkelman and H. Jonsson, J. Chem. Phys., 2000, 113, 9978-9985.

60 M. D. Segall, R. Shah, C. J. Pickard and M. C. Payne, Phys. Rev. B: Condens. Matter Mater. Phys., 1996, 54, 16317-16320.

61 M. D. Segall, P. J. D. Lindan, M. J. Probert, C. J. Pickard, P. J. Hasnip, S. J. Clark and M. C. Payne, J. Phys.: Condens. Matter, 2002, 14, 2717-2744.

62 S. Plimpton, J. Comput. Phys., 1995, 117, 1-19.

63 W. J. Mortier, S. K. Ghosh and S. Shankar, J. Am. Chem. Soc., 1986, 108, 4315-4320.

64 A. C. T. van Duin, V. S. Bryantsev, M. S. Diallo, W. A. Goddard, O. Rahaman, D. J. Doren, D. Raymand and K. Hermansson, J. Phys. Chem. A, 2010, 114, 9507-9514.

65 O. Rahaman, A. C. T. van Duin, W. A. Goddard and D. J. Doren, J. Phys. Chem. B, 2011, 115, 249-261.

66 L. Huang, K. L. Joshi, A. C. T. van Duin, T. J. Bandosz and K. E. Gubbins, Phys. Chem. Chem. Phys., 2012, 14, 11327-11332.
67 P. C. Lebrun, W. D. Lyon and H. A. Kuska, J. Crystallogr. Spectrosc. Res., 1986, 16, 889.

68 G. S. Girolami, P. M. Jeffries and L. H. Dubois, J. Am. Chem. Soc., 1993, 115, 1015-1024.

69 K. Nakamoto and A. E. Martell, J. Chem. Phys., 1960, 32, 588-597.

70 C. Lee and H. H. Lee, Electrochem. Solid-State Lett., 2005, 8, G5-G7.

71 C. R. Vestal and T. C. DeVore, Proceedings of the Conference on High Temperature Corrosion and Materials Chemistry, Electrochemical Society, Washington DC, 2001.

72 J. Pinkas, J. C. Huffman, D. V. Baxter, M. H. Chisholm and K. G. Caulton, Chem. Mater., 1995, 7, 1589-1596.

73 J. Huo, R. Solanki and J. McAndrew, J. Mater. Res., 2002, 17, 2394-2398.

74 J. Kwon, M. Dai, M. D. Halls and Y. J. Chabal, Chem. Mater., 2008, 20, 3248-3250.

75 D. N. Goldstein, J. A. McCormick and S. M. George, J. Phys. Chem. C, 2008, 112, 19530-19539.

76 T. Törndahl, M. Ottosson and J. O. Carlsson, J. Electrochem. Soc., 2006, 153, C146-C151. 